\title{
THE ROLE OF EMOTIONAL COMMITMENT IN RELATIONSHIP MARKETING: AN EMPIRICAL INVESTIGATION OF A LOYALTY MODEL FOR CASINOS
}

\author{
Jun Jian Sui \\ Seyhmus Baloglu \\ University of Nevada, Las Vegas
}

\begin{abstract}
This study examines the antecedents and consequences of commitment to hotel casinos targeting local customers. To accomplish this goal, a model of loyalty was developed and tested to understand the behavioral outcomes (benefits) of building relationships with local customers and what elements contribute to these behavioral outcomes. The results of path analysis showed that emotional attachment is a key mediating variable between attitudinal antecedents (trust and switching costs) and behavioral variables (proportion of visit, word of mouth, cooperation, time spent in casinos, and other product usage). The most influential variables on behavioral outcomes of loyalty were found to be trust and emotional attachment. The study contributes to services and casino marketing by validating empirical linkages in gaming context and providing empirical support for conceptualized differential effects of trust and switching cost on emotional attachment and behavioral outcomes of loyalty in services marketing literature. Theoretical and practical implications and future research issues are discussed.
\end{abstract}

KEYWORDS: trust; switching cost; emotional commitment; behavioral loyalty; casinos; path analysis

The relational aspect of buyer-seller exchanges has received considerable attention in the marketing literature. Building and maintaining customer loyalty based on relationship marketing philosophy has become the focal point of managing businesses across industries. The underlying strategy has been a dramatic change in focus from discrete transactions to ongoing relationships in the businessto-consumer and business-to-business exchange process. The benefits or consequences of relationship marketing to service companies include customer reten-

Authors' Note: This study is based on a consulting project for a gaming corporation that provided funding and support. The first author also based his masters' thesis on the project, which received 2001 Master Thesis Meritorious Award of Travel and Tourism Research Association (TTRA) and Best Thesis Award at William F. Harrah College of Hotel Administration, University of Nevada at Las Vegas.

Journal of Hospitality \& Tourism Research, Vol. 27, No. 4, November 2003, 470-489

(C) 2003 International Council on Hotel, Restaurant and Institutional Education

470 
tion, reduced marketing costs, more purchases over time, positive word of mouth, and business referrals (Reichheld \& Sasser, 1990). Bendapudi and Berry (1997) came up with three critical reasons for unique importance of relationship marketing to service industries. First, many services by their nature require ongoing membership. Second, because of the intangibility nature of services, customers may continue their relationship with service providers to reduce the risk of trying other competitors. Third, the customers may form relationships at organizational and individual employee levels.

Across products and services, the stiffer competition forces companies to adopt relationship marketing as a competitive and growth strategy, or even a marketing and management philosophy. Since the early 1990s, the casino industry has become an industry of a fierce and intense competition (Border, 1990; Bowen, 1994; McKim, 1999). This forced casino companies to put more emphasis on relationship marketing and build barriers and switching costs to not lose their customers to the competition (Bowen, 1994; Heun, 2000). The relationship marketing was suggested as a cure to increase casino profits for middle- and low-level customer segments (Border, 1990). The casinos currently attempt to reach beyond the $3 \%$ to $10 \%$ of their high-roller customers and develop loyalty among the occasional players, a much larger middle-market segment (McKim, 1999). Much effort to increase loyalty and switching costs concentrates on frequent player reward and recognition programs. These programs - designed for mass market based on comps, incentives, giveaways, and discounts-now dominate the casino industry to keep the customers and have them spend the majority of their time at a particular property (Heun, 2000; McKim, 1999). A few casinos also change their strategy from "the loosest slots in town" to "a memorable experience" to cultivate brand loyalty (McKim, 1999).

Javalgi and Moberg (1997), in their conceptual article, argued that loyalty differences between services would exist and the relationship between attitudinal and behavioral loyalty would be different because of the level of competition in a particular service segment. Arguing that service loyalty should be examined individually for each service segment, Ruyter, Wetzels, and Bloemer (1998) provided some empirical evidence that the linkages between service loyalty and its antecedents, such as service quality and switching cost, vary significantly—weaker, stronger, or no relation at all-across service industries. These all suggest that the nature of relationship marketing and antecedents and outcomes of customer loyalty should be studied across different service operations to gain better strategic insights and to better understand its implications.

Although several calls have been made by scholars for more attention to the relationship marketing and loyalty in services, there has been limited empirical research examining antecedents and consequences of loyalty in business-tocustomer markets and service contexts (Morgan \& Hunt, 1994; Pritchard, Havitz, \& Howard, 1999; Ruyter et al., 1998). In the hospitality field, only a couple of studies empirically investigated the linkages between the antecedents and consequences of relationship marketing and loyalty, and their findings were limited to luxury hotels (Bowen \& Shoemaker, 1998; Kim, Han, \& Lee, 2001). More important, most empirical studies on loyalty viewed commitment or loyalty as a cogni- 
tive construct; as a result, the emotional commitment or attachment has received relatively little attention. In addition, most work on loyalty and relationship marketing has revolved around constrained-based (i.e. switching cost) or dedicationbased (trust) aspects of customer relationship. Bendapudi and Berry (1997), based on their conceptual framework of relationship marketing, suggested that constrained- and dedication-based relationships should be investigated to better understand customer relationship behavior because they would lead to different benefits or outcomes.

To address these gaps in the literature, this study developed a loyalty model based on prior work on relationship marketing and loyalty and tests the model in the context of casinos to understand the outcomes (benefits) of building relationships with casino customers and what elements contribute to those outcomes. The study incorporates constrained-based (i.e. switching cost) and/or dedicationbased (trust) aspects of customer relationship in the model. The specific objectives of the study are to

- delineate the role of emotional commitment in relationship marketing,

- examine whether the empirical linkages found in previous research on service loyalty will hold in the casino context, and

- seek empirical support for the conceptualized differential effects of trust, switching cost, and emotional attachment on behavioral outcomes (benefits) of loyalty.

\section{LITERATURE REVIEW}

This discussion first presents conceptual and empirical studies determining general theoretical framework for the model (Bendapudi \& Berry, 1997; Bowen \& Shoemaker, 1998; Dick \& Basu, 1994; Geyskens, Steenkamp, Scheer, \& Kumar, 1996; Morgan \& Hunt, 1994) and then define model constructs and specific linkages among the constructs.

\section{The Framework and Model}

Dick and Basu (1994) offered a framework for customer loyalty relationship by integrating attitudinal and behavioral constructs. The framework included cognitive (such as confidence), affective (such as emotion and satisfaction), and conative (such as switching cost) attitudinal antecedents as well as behavioral consequences (such as repeat patronage and word of mouth). The commitmenttrust theory of Morgan and Hunt (1994) proposed commitment and trust as key mediating variables (KMV) between relationship antecedents and outcomes. The empirical work of Geyskens et al. (1996) provided that trust and dependence influence emotional commitment, but trust had a stronger effect. Bendapudi and Berry's (1997) conceptual model suggested that dependence-based (such as switching cost) and dedication-based (such as trust and emotional attachment) customer relationships would lead to different behavioral outcomes (i.e., the repeat purchase would be a result of switching cost, trust, and/or emotional commitment whereas positive word of mouth would be a result of trust or emotional commitment). Bowen and Shoemaker (1998) investigated antecedents and conse- 
quences of commitment and trust in service relationships, as applied to relationship between luxury hotels and their guests. They found that trust, switching costs, benefits, and perceptions of value positively influence commitment that, then, influence behavioral outcomes of loyalty. Kim et al. (2001) have developed and tested a model of relationship marketing for luxury hotels and found that the quality of relationship positively influences the commitment, word of mouth, and repeat purchase. Their findings also show that higher commitment leads to more positive word of mouth and repeat purchase, which provided support for the intervening role of commitment in service setting.

The model illustrated in Figure 1 posits that building affective or emotional attachment is central to building relationships. The antecedents to emotional commitment are trust and switching cost. The behavioral outcomes include word of mouth, cooperation (willingness to help the casino), proportion of visit (the number of visits to a particular casino brand each week as compared to total number of visits to casinos per week), time spent in the casino per visit, and use of other products and services. The linkages represent positive hypothesized relationships that are based on conceptual and empirical support in the literature.

\section{Model Constructs}

Trust. The concept of trust has been a focal point in most loyalty studies. Trust was defined to contain several elements such as honesty (fulfilling promises), competency, benevolence, reliability, dependability, and customer orientation (Anderson \& Narus, 1990; Swan \& Nolan 1985; Swan, Trawick, Rink, \& Roberts, 1988). Morgan and Hunt (1994) defined trust as one's confidence in an exchange partner's reliability and integrity. In conceptual framework for customer retention proposed by Hennig-Thurau and Klee (1997), trust was defined (following Moorman, Zaltman, \& Deshpande, 1992) as the willingness to rely on exchange partner in whom one has confidence. The authors suggested that trust would foster or promote cognitive and affective commitment. The commitmenttrust theory of Morgan and Hunt (1994) proposed commitment and trust as key constructs of relationship marketing. They suggested a model of key mediating variables (KMV) where commitment and trust mediated the relationship between relationship antecedents and outcomes. Morgan and Hunt (1994) found that trust is a major determinant of commitment. Bowen and Shoemaker (1998) demonstrated that trust positively influence the commitment to luxury hotels. Several other researchers have found that trust is positively related to behavioral outcomes, such as cooperation (joint and collaborative behavior) and intent to cooperate in buyer and supplier context (Andaleeb, 1995; Anderson \& Narus, 1990).

Switching Cost. Switching costs are often included in conceptual models of loyalty to refer to dependency of customers on providers or barriers built for the customers to stay in the relationship (Bendapudi \& Berry, 1997; Dick \& Basu, 1994; Geyskens et al., 1996). Switching costs were defined as customers' perception of time and effort costs associated with changing from current company to competition (Bowen \& Shoemaker, 1998; Porter, 1985). Convenience was also suggested as another component of switching costs (Dick \& Basu, 1994; Lee 
Figure 1

A Model of Service Loyalty

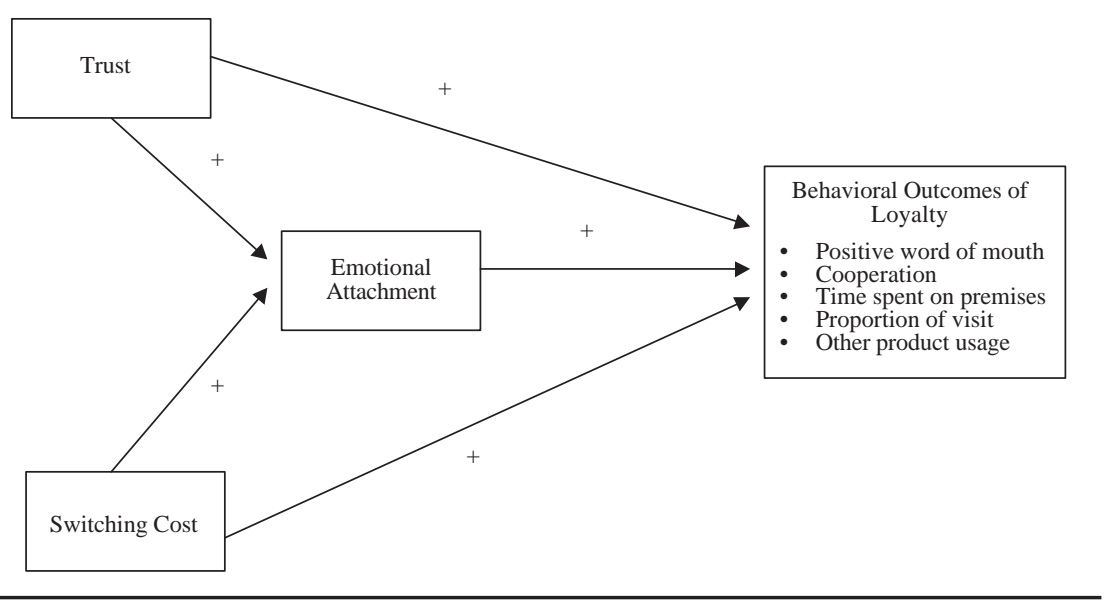

\& Cunningham, 2001). In conceptual models, switching cost or customers' constrained-based motivations (they "have" to stay in the relationships) were suggested to have a positive impact on commitment and behavioral loyalty (Bendapudi \& Berry, 1997; Dick \& Basu, 1994). Bowen and Shoemaker (1998) found that switching costs positively influence commitment toward luxury hotels. Geyskens et al. (1996) found that the perceived dependence has a positive impact on affective commitment.

Emotional Attachment. Although terms such as commitment, brand loyalty, and affective (emotional) attachment were often used interchangeably in the loyalty and relationship literature (Pritchard, Howard, \& Havitz, 1992), the emotional attachment or commitment to a product or brand has been cited as a key element to develop and maintain customer loyalty (Bendapudi \& Berry, 1997; Dick \& Basu, 1994; Geyskens et al., 1996). Geyskens et al. (1996) divided commitment into two components in business-to-business relationships: affective and calculative commitment. The former is the extent to which members like to maintain their relationship with specific partners, whereas the latter is the extent to which they need to maintain a relationship. Similarly, Hennig-Thurau and Klee (1997) disintegrated the concept of commitment into customers' emotional (affective aspect) and rational (cognitive aspect) bond to the relationship. Affective or emotional commitment has often been defined as liking the partner, enjoying the partnership, and having a sense of belongingness (Geyskens et al. 1996; Jaros, Jermier, Koehler, \& Sincich, 1993). The positive relationship between commitment and behavioral outcomes of loyalty (repeat purchase, ancillary product use, word of mouth, cooperation) has been strongly supported in the literature (Bowen \& Shoemaker, 1998; Dick \& Basu, 1994; Kim et al., 2001; Morgan \& Hunt, 1994). Bendapudi and Berry (1997) proposed that cooperation (working together) and word of mouth (advocacy) would be an outcome of affective com- 
mitment. The findings of Geyskens et al. (1996) demonstrated that interdependence and trust positively influence affective commitment whereas trust had a stronger effect on affective commitment than on calculative commitment. The authors suggested that the firms should focus on developing the affective commitment and claimed that building trust rather than interdependence would cultivate such a commitment.

Behavioral Outcomes of Loyalty. Conceptual and empirical work presented suggest that switching cost, trust, and emotional attachment have significant impacts on behavioral outcomes of loyalty (Bowen \& Shoemaker, 1998; Dick \& Basu, 1994; Geyskens et al., 1996; Morgan \& Hunt, 1994). The loyal customers make repeat purchases, purchase other products and services of the company, spread positive word of mouth, help the company, and make business referrals (Bendapudi \& Berry, 1997; Bowen \& Shoemaker, 1998; Dick \& Basu, 1994; Reichheld \& Sasser, 1990).

The conceptual framework suggested by Bendapudi and Berry (1997) categorized customers' motivations for maintaining relationships with service providers into two groups: constrained-based (they "have to" stay in the relationship) and dedication-based (they "want" to stay in the relationship). The authors claimed both sets of motivations should be considered to better understand customer relationship behavior. The constraint-based (or dependency) relationship included, among others, switching cost whereas the dedication-based relationship included concepts such as trust and affective attitudinal commitments. The authors claimed that these two distinct but interrelated relationships would lead to different outcomes. For example, they proposed that cooperation (working together) and word of mouth (advocacy) would be an outcome of dedication-based relationship. Cooperation is defined as working together to achieve mutual goals (Anderson \& Narus, 1990). Advocacy includes promoting the company, spreading positive word of mouth, and business referrals (Bendapudi \& Berry, 1997).

The repeat purchase measure (actual or intentional), although used very frequently, has been criticized for being invalid measure of behavioral loyalty because it ignores relative behavior. The proportion of purchase, on the other hand, has been suggested a more valid measure of behavioral loyalty because it takes competitive effects and shared loyalty into the consideration (Day, 1969; Pritchard \& Howard, 1997; Pritchard et al., 1992). The proportion of purchase, reflecting actual behavior, is a ratio of a particular-brand purchase frequency to product-class purchase frequency (Day, 1969; Pritchard et al., 1999). The findings of Kim et al. (2001) indicated that higher commitment leads to more positive word of mouth and repeat purchase. Morgan and Hunt's (1994) study showed a positive linkage between commitment and voluntary partnership. Bowen and Shoemaker (1998) found that the high levels of commitment lead to increased product use and voluntary partnership (a composite measure of word of mouth and cooperation). For hospitality and tourism companies, the use of other product and services by loyal customers may indicate that loyal customers are also more likely to spend more time on premises. 


\section{METHODOLOGY}

\section{Sample and Instrument}

The population for this study was slot club members of a gaming corporation headquartered in Las Vegas. The corporation owns and manages multiple properties targeting mainly local customers. The sampling frame included those members who reside in Las Vegas metropolitan area and who visited one of the corporation's properties located in that area in the past 3 months. A sample of 1,500 members was selected by using simple random procedure.

The study used mail survey design method. A questionnaire was developed based on literature review, input from three faculty members, and the corporation's Relationship Marketing department. The instrument was then pretested for clarity, wording, flow, and completion time at one of the properties of the corporation. The surveys were distributed at three different places, including the main entrance, parking lot, and cash-back counter (where club member customers get their cash back because they have spent a specific amount of money on gambling). The questionnaire was revised slightly after the pretest and finalized.

The questionnaire is divided into five parts. The first part of the questionnaire included questions on frequency of casino visits in general and a screening question of whether respondents visited one of the local casinos of the corporation in the past 3 months. The second part asked the respondents to name a particular casino, which will be used for the remainder of the questionnaire, belonging to the corporation to which they have an affinity and/or enjoy going. They were then asked to provide information about their general gambling behavior toward the local casino of their choice, such as frequency of visits, time spent on each visit, reason for gambling, types of casino games played most frequently, bet size, and gambling budget. The third part sought information on attitudinal constructs such as trust, switching behavior, and emotional attachment and behavioral outcomes of loyalty, such as word of mouth and voluntary partnership. The fourth part sought information on behavioral outcomes of loyalty related to ancillary products/services other than gambling. Finally, the fifth part included questions about demographic profile of the respondents.

\section{Measurement}

The measurement of model variables included multi-item measures, singleitem measures (e.g., time spent in casino), and single index measures (e.g. proportion of visit). The measurements of model constructs were provided in the appendix. The variables_-such as trust, switching cost, emotional attachment, word of mouth, and cooperation-were measured by multiple items on a 7-point scale ( 1 = strongly disagree and 7 = strongly agree $)$. A “don't know" option was also provided. It should be noted that, to avoid response bias and artificial reliability, the questions were presented in random order on the questionnaire. The variable scores were computed by summing the item scores.

Trust was measured by five items based on conceptual definitions and items adapted from Bowen and Shoemaker (1998) to the casino setting. Switching cost 
was measured by one item in Bowen and Shoemaker (1998). To assess the reliability of this scale, a second item was developed based on construct definition reflecting convenience. Emotional attachment (affective commitment) was measured by five items based on construct definition, Bowen and Shoemaker (1999) and Pritchard and Howard (1997). Advocacy (word of mouth) and cooperation were measured by three items each based on construct definitions and Bowen and Shoemaker (1998).

The proportion of visit, adapted from Day (1969), was measured as a ratio of casino-brand visit frequency to product-class visit frequency. Product-class and brand-visit frequencies were measured by two questions placed in different sections of the questionnaire: number of visits per week/month to the particular casino to which they feel loyal (brand) and number of visits per week/month to casinos in Las Vegas Metropolitan Area (product class). The monthly frequencies were converted to weekly frequencies before computing the proportion of visit variable.

The time spent in casino was measured by average number of hours the respondents stay in the particular local casino brand per visit. For other product/service usage, the respondents were asked to indicate, compared to other casinos, if they spend the same amount or more on each product at the particular local casino brand to which they claimed loyalty. A list of eight products was provided (see the appendix). A 7-point scale ( $1=$ spend the same and $7=$ spend more $)$ was used and the options "don't know" and "service not available" were also provided. An index score was computed by averaging the product/services used for each respondent.

\section{Data Collection Procedure and Analysis}

The questionnaires, including a cover letter and a postage-paid return envelope, were sent to randomly selected 1,500 slot club members on December 3, 1999. After a 3-week cut-off period, a total of 314 questionnaires were returned (20.9\% response rate). Twenty-one questionnaires were discarded because of missing responses. No packets were returned due to incorrect addresses or any other reason. Thus, the useable response rate represents 19.5\%. Follow-up mailings were not used because of the adequate sample size generated by first-wave mailing for model testing.

Path analysis was used to test the hypothesized relationships and overall pattern of the model. Using SPSS 10.0, path coefficients were estimated by partial regression coefficients (PLS) between the cause (exogenous) variables and the effect (endogenous) variables on which they have impact (Asher, 1983; Davis, 1985; Pedhazur, 1982). A path coefficient was considered significant at the .05 or better probability level. The path analysis was conducted by freeing all possible paths (also called PLS procedure). Ryan, Ryner, and Morrison (1999) demonstrated that the PLS approach, which simultaneously tests all linkages (e.g. freeing all paths), was a more reliable and valid approach than the principal component regression and full regression in terms of predicting loyalty. This procedure helps researcher reveal the overall pattern of the model and validate the intervening variables by examining direct, indirect, and total effects of exogenous (inde- 
pendent) on endogenous (dependent) variables (Holbrook, 1981; Ryan et al., 1999; Sirgy \& Samli, 1985).

The data were examined for several assumptions of path analysis, such as normality, linearity, homoskedasticity, and multicollinearity (Hair, Anderson, Tatham, \& Black, 1992; Pedhazur, 1982). The only violation of normality and linearity assumption, although not very significant, was detected when regressing proportion of visit variable on trust, switching cost, and emotional attachment. The reason was that the proportion of visit ratio was $100 \%$ for almost one half of the respondents. Although various transformations were attempted, no improvement was gained.

\section{RESULTS AND DISCUSSION}

\section{Demographic Profile and Nonresponse Bias}

The demographic profile of respondents showed that the majority are women, married, retired, and 55 years of age or older with some college degree. They mostly visit casinos for a combination of monetary gain and pleasure/entertainment and prefer video poker and nickel/quarter denomination machines. To check nonresponse bias, the corporation compared demographic and gaming preference profile of the respondents to the slot club member profile in their database. Both profiles were found very similar. Nevertheless, the readers should take a caution because the respondents would be similar to those who did not respond on demographic and gaming preference characteristics; however, they may not be similar in terms of their attitudinal responses.

\section{The Descriptive Statistics, Reliability, and Validity}

The statistics for descriptives and reliability and validity assessment of multiitem constructs are summarized in Table 1. The reliabilities of multi-item constructs were assessed by Cronbach's alpha. The alpha reliabilities of the multiitem measures ranged from .89 to .66 . All reliability levels were above the critical level of .70 (explaining at least $50 \%$ of variance) except for switching cost $($ alpha $=.66)$ (Nunnaly, 1978). Because this scale was newly developed as a multiscale measure, the reliability level was acceptable (Churchill, 1979). In addition, the item-to-total correlations were high, and no improvement in reliability could be gained by dropping any item. The convergent and discriminant validity of the multi-item constructs were assessed by comparing reliability coefficients with correlations between constructs and by examining multitraitmonomethod matrices (within- and between-construct item correlations). For most variables, the reliability scores were higher than interconstruct correlations, and the correlations between items within the same construct were higher than the items belonging different constructs. The exogenous variables had different effects on endogenous variables (behavioral outcomes), providing some support for discriminant validity. Overall, the constructs exhibited satisfactory convergent and discriminant validity. 
Table 1

The Summary of Descriptive, Reliability, and Validity Statistics for Model Variables

\begin{tabular}{|c|c|c|c|c|c|c|c|c|}
\hline & $\mathrm{T}$ & SC & $\mathrm{EA}$ & WOM & $\mathrm{C}$ & POV & TS & OPU \\
\hline Trust (T) & 1 & & & & & & & \\
\hline Switching cost (SC) & 0.35 & 1 & & & & & & \\
\hline Emotional attachment (EA) & 0.78 & 0.46 & 1 & & & & & \\
\hline Word of mouth (WOM) & 0.79 & 0.34 & 0.89 & 1 & & & & \\
\hline Cooperation (C) & 0.66 & 0.47 & 0.74 & 0.71 & 1 & & & \\
\hline Proportion of visit (POV) ${ }^{a}$ & 0.18 & 0.30 & 0.34 & 0.25 & 0.24 & 1 & & \\
\hline Time spent $(\mathrm{TS})^{\mathrm{b}}$ & 0.28 & 0.31 & 0.41 & 0.29 & 0.24 & 0.23 & 1 & \\
\hline Other product usage (OPU) & 0.44 & 0.31 & 0.53 & 0.47 & 0.51 & 0.25 & 0.33 & 1 \\
\hline Scale & 1 to 7 & 1 to 7 & 1 to 7 & 1 to 7 & 1 to 7 & 0 to $100 \%$ & 1 to 10 & 1 to 7 \\
\hline M & 5.07 & 4.39 & 4.75 & 5.02 & 4.36 & $80 \%$ & 3.72 & 4.01 \\
\hline$S D$ & 1.37 & 1.47 & 1.43 & 1.57 & 1.69 & $26 \%$ & 1.75 & 1.70 \\
\hline Cronbach's alpha & 0.8901 & 0.6606 & 0.8699 & 0.8844 & 0.7242 & - & - & - \\
\hline Item-to-total correlation (range) & 0.53 to 0.79 & 0.44 & 0.62 to 0.76 & 0.76 to 0.81 & 0.51 to 0.59 & & & \\
\hline Within-item correlations (range) & 0.766 to 0.506 & 0.418 & 0.496 to 0.755 & 0.680 to 0.745 & 0.477 to 0.519 & & & \\
\hline Between-item correlations (range) & 0.174 to 0.509 & 0.139 to 0.374 & 0.304 to 0.502 & 0.394 to 0.601 & 0.394 to 0.601 & & & \\
\hline
\end{tabular}

Note: The sample size $(N)$ is 163 for all correlation coefficients because of listwise deletion of missing variables. All correlation coefficients are significant at .05 or better probability level.

a. Proportion of visit $(\mathrm{POV})=($ number of visits to a particular casino brand / number of visits to casinos $) \times 100$.

b. Average number of hours stayed in a particular casino brand per visit (TS). 
The findings showed strong support for nomological validity of the model. Nomological validity is confirmation of significant correlations and paths between the constructs in theoretically predicted ways (Malhotra, 1999; Smith \& Barclay, 1997). Most path coefficients were significant $(p<.05)$ and in the expected direction on theoretical grounds. In addition, variances explained in most of the endogenous variables were strong and/or consistent with previous studies of loyalty.

Although there is no summary statistics to assess the overall fit of the model when PLS is used, one can compare the magnitude of path coefficients and correlations among constructs to assess overall pattern of the model and validate the intervening role of variables as hypothesized. In a path model, if the chain model correctly represents the "true" causal flow, then correlation between variables are expected to approach zero as the distance between them in the causal chain increases (Davis, 1985). All path coefficients from emotional attachment to behavioral outcome variables were higher than those from trust and switching cost to the behavioral outcome variables. Also, the magnitudes of linkages from trust and switching cost to emotional attachment were higher than those from trust and switching cost to the behavioral outcome variables. Equally important, emotional attachment was the only variable influencing all behavioral outcomes of loyalty when each outcome was regressed on all variables preceding it in the model. Thus, in the context of recursive modeling (no reciprocal linkages), the results showed strong validity for the model and the intervening role of the emotional attachment from theoretical and statistical standpoints. However, it should be regarded as one possible valid model — not the most valid model because alternative models, particularly nonrecursive ones-may also fit the data equally well or better.

\section{The Model Testing}

The Figure 2 shows the results of path analysis. Trust $(\beta=0.70, p<.001)$ and switching cost $(\beta=0.23, p<.001)$ had positive effects on emotional attachment $\left(R^{2}=0.65\right)$. The effect of trust was three times as much that of switching cost. Trust $(\beta=0.21, p<.001)$ and emotional attachment $(\beta=0.79, p<.001)$ positively influenced word of mouth and explained $85 \%$ of the variance. Cooperation was positively influenced by trust $(\beta=0.19, p<.05)$, switching $\operatorname{cost}(\beta=0.18, p<.05)$, and emotional attachment $(\beta=0.47, p<.001)$. These variables together explained $57 \%$ of variance in cooperation. Switching $\operatorname{cost}(\beta=0.25, p<.05)$ and emotional attachment $(\beta=0.31, p<.05)$, explaining $14 \%$ of variance, had positive effect on proportion of visit. Time spent was positively influenced by emotional attachment $(\beta=0.35, p<05)$, which explained about $15 \%$ of variance. Emotional attachment $(\beta=0.36, p<.05)$ was the only variable influencing the other product usage and explaining about $15 \%$ of variance.

Direct, indirect, and total effects of exogenous (independent) variables on endogenous (dependent) variables were examined to delineate the overall pattern of the model (Table 2). The indirect effect of trust on word of mouth was greater than its direct effect. After taking the indirect effect of trust on word of mouth 
Figure 2

The Statistical Relationships Among Model Variables for Casinos $(N=163)$

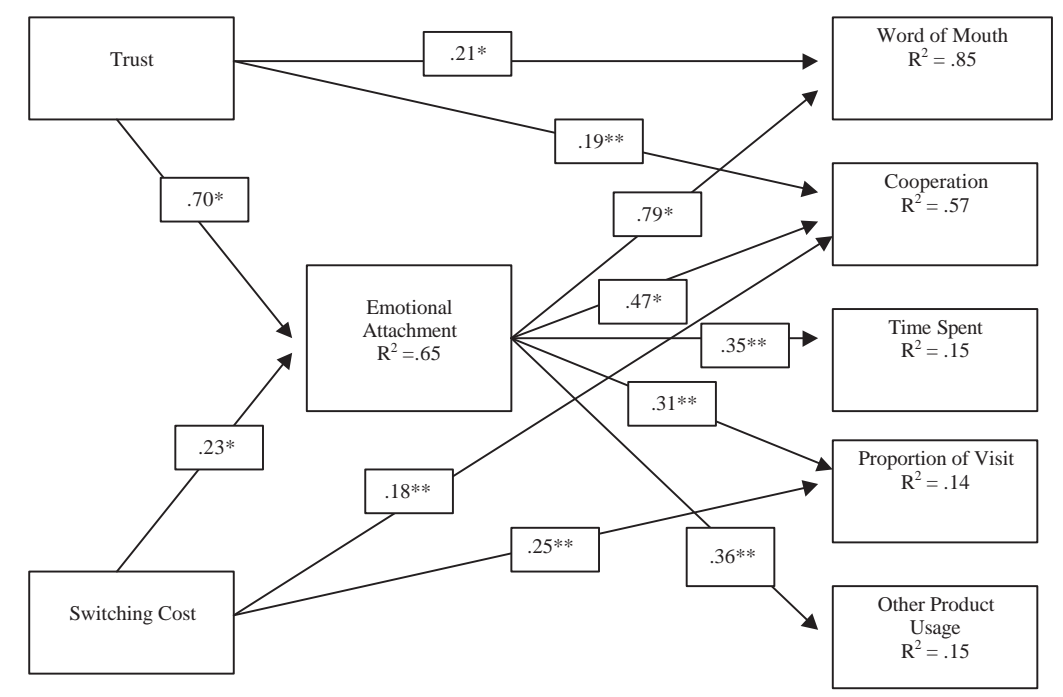

Note: The standardized coefficients with "*” are significant at .001 probability level whereas the ones with "**” are significant at .05 probability level. $R^{2}$ is adjusted $R^{2}$.

through emotional attachment $(0.70 \times 0.79)$, the total effect of Trust $(0.76)$ became as strong as that of emotional attachment (0.79) in influencing word of mouth. Again, trust (0.52) and emotional attachment (0.47) equally influenced cooperation based on their total effects. The indirect effect of switching cost (0.11) was smaller than its direct effect $(0.18)$ on cooperation whereas trust had larger indirect effect $(0.33)$ than its direct effect $(0.19)$ on cooperation. After adding its indirect effect through emotional attachment, the total effect of switching cost (0.32) on proportion of visit was found to be as strong as that of emotional attachment (0.31). This was largely due to switching cost's direct effects because its indirect effect on proportion of purchase was smaller than trust's indirect effects. The other product usage and time spent in casino were to a great extent influenced by emotional attachment given that it was the only variable directly influencing these revenue growth variables and its total effect was larger than those of trust and switching cost. It should also be noted that the indirect effects of trust on time spent in casino and other product usage $(0.25$ each) was larger than those of switching cost ( 0.08 each).

The findings supported the hypothesized intervening role of emotional commitment to casinos in the model. Unlike trust and switching cost, it influenced all behavioral outcomes of loyalty in the model. Based on the magnitudes of direct path coefficients, the emotional attachment was much more influential than other exogenous variables in predicting behavioral outcomes of loyalty. In addition, in most cases the indirect effects of trust and switching cost on behavioral outcomes 
Table 2

Direct, Indirect, and Total Effects of Exogenous Variables on Endogenous Variables in the Model $(N=163)$

\begin{tabular}{|c|c|c|c|c|c|c|c|c|c|c|c|c|c|c|c|c|}
\hline \multirow{3}{*}{$\begin{array}{l}\text { Exogenous } \\
\text { Variables }\end{array}$} & \multirow[b]{3}{*}{ EA } & \multicolumn{15}{|c|}{ Endogenous Variables } \\
\hline & & \multicolumn{3}{|c|}{ WOM } & \multicolumn{3}{|c|}{ C } & \multicolumn{3}{|c|}{ POV } & \multicolumn{3}{|c|}{ TS } & \multicolumn{3}{|c|}{ OPU } \\
\hline & & $\mathrm{D}$ & I & $\mathrm{T}$ & $\mathrm{D}$ & I & $\mathrm{T}$ & $\mathrm{D}$ & 1 & $\mathrm{~T}$ & $\mathrm{D}$ & I & $\mathrm{T}$ & $\mathrm{D}$ & I & $\mathrm{T}$ \\
\hline $\mathrm{T}$ & 0.70 & 0.21 & 0.55 & 0.76 & 0.19 & 0.33 & 0.52 & - & 0.22 & 0.22 & - & 0.25 & 0.25 & - & 0.25 & 0.25 \\
\hline SC & 0.23 & - & 0.18 & 0.18 & 0.18 & 0.11 & 0.29 & 0.25 & 0.07 & 0.32 & - & 0.08 & 0.08 & - & 0.08 & 0.08 \\
\hline EA & & 0.79 & - & 0.79 & 0.47 & - & 0.47 & 0.31 & - & 0.31 & 0.35 & - & 0.35 & 0.36 & - & 0.36 \\
\hline$R^{2}$ & 0.65 & 0.85 & & & 0.58 & & & 0.16 & & & 0.16 & & & 0.17 & & \\
\hline Adjusted $R^{2}$ & 0.65 & 0.85 & & & 0.57 & & & 0.14 & & & 0.15 & & & 0.15 & & \\
\hline F-Test & 186.2 & 307.8 & & & 68.8 & & & 9.9 & & & 11.1 & & & 10.3 & & \\
\hline Significance & 0.000 & 0.000 & & & 0.000 & & & 0.001 & & & 0.001 & & & 0.001 & & \\
\hline
\end{tabular}

Note: Table shows path coefficients that are significant at .05 or better probability level. D: direct effect, I: indirect effect, $T(D+l)$ : total effect, $T$ : trust, SC: switching cost, EA: emotional attachment, WOM: word of mouth, C: cooperation, POV: proportion of purchase, TS: time spent, OPU: other product usage. 
of loyalty were larger than their direct effects. In a path model, if the chain model correctly represents the "true" causal flow, then correlation between variables are expected to approach zero as the distance between them in the causal chain increases (Davis, 1985). The general pattern of the model mostly met that requirement, which provided support for the intervening role of emotional attachment.

As the dependence on and trust to the casino augments, the emotional attachment or commitment of customers to the casino increases. This finding was in line with previous research (Geyskens et al., 1996). Thus, maintaining or developing emotional attachment requires casinos to cultivate trust and dependence. However, trust appears to be more influential than dependence relationship, and as influential as the emotional commitment. Therefore, casinos should aim much of their effort on building trust, which will also ultimately enhance emotional commitment. To the our knowledge, however, the casinos evaluated in this study mostly focus their strategies on dependence relationship such as convenience, point systems, and a variety of sales promotions. The findings empirically confirm the proposition of Bendapudi and Berry (1997) that dependence, trust, and emotional attachment would have different effects on various behavioral outcomes of loyalty. The casino customers are more likely to recommend and spread positive comments when they have higher levels of trust and emotional attachment to the company. It is a well-known fact that word of mouth is more critical for service industries. To achieve this critical long-term goal, casino management should develop strategies to increase trust and emotional attachment given their equal direct effects on word-of-mouth behavioral outcome. The higher levels of trust and emotional attachment are also related to customers' increased willingness to perform partnership activities and work together with the company. Although switching cost directly influenced cooperation, the cooperative behavior of customers is largely influenced by emotional attachment, and trust when its indirect effect was taken into account. This again suggests that casinos should augment emotional attachment and, therefore, a feeling of trust toward their organizations. These results show that trust is more important than switching cost in terms of influencing long-term strategic behavioral outcomes of loyalty (i.e., word of mouth and cooperation) and future business. One possible explanation of direct effect of switching cost on cooperative behavior of players would be because of the fact that local casinos in this study frequently use winning customers in their internal and external promotion strategies, which was one of the items measuring cooperation in this study. Therefore, the respondents who are more dependent on the casino might have been more receptive to such an idea.

On the other hand, customers' proportion of visits to a particular casino is positively associated to dependence relationship (switching cost) and emotional attachment. In other words, building barriers to make it difficult for the customer to switch to another casino and developing emotional attachment make the customer visit the casino more frequently. It should be noted that customers could easily break themselves free from dependency relationships by switching to competitors offering better or similar deals. If this is solely used for maintaining relationship, the customers can easily be lost to the competition. In this regard, the emotional commitment of the customer, which is harder to change by the compe- 
tition, is more influential than his or her dependence on the casino. However, the strategies to further increase these outcomes should not be limited to growing emotional attachment and dependence relationships. The reason is that when the indirect effect of trust through emotional attachment was included in the equation, trust also becomes influential on increasing number of visits compared to competition.

The higher levels of emotional attachment result in longer stay and more spending of customers on revenue centers other than gaming. It should be noted that the other revenue centers are becoming more important for almost every casino in Las Vegas. The findings of this study show that cultivating emotional commitment is the key strategy in increasing customer spending on other revenue centers and keeping them in local casinos longer.

\section{CONCLUSION}

This study investigated the antecedents and consequences of relationship marketing for casinos. The study makes contributions to existing literature from theoretical, methodological, and practical standpoints. First, this study extends the external validity of some empirical linkages found for different service classes by testing a service loyalty model for the casinos. Second, the study provides empirical support for the conceptualized differential effects of trust, switching cost, and emotional attachment on various behavioral outcomes of loyalty in service loyalty literature. Third, it was demonstrated that the emotional attachment to a company is a key mediating variable positively influencing all behavioral loyalty variables included in the study. Fourth, time spent on premises during a visit in a service organization was included and tested for the first time in a loyalty model. This behavioral variable is critical not only to casinos but also to other hospitality organizations, such as hotels, restaurants, and bars. Therefore, it should be integrated into theoretical framework and empirical models of service loyalty and relationship marketing, where appropriate.

From methodological perspective, this study examined direct and indirect effects of antecedent variables in the model. This examination, as the analyses showed, significantly changed the interpretation of findings, particularly the role of trust on several behavioral outcomes of loyalty on which it had no direct impact.

The study also provides tactical and strategic implications to casinos. The findings demonstrate that emotional attachment of customers to the casino is the most critical attitudinal dimension of relationship marketing as it positively influenced all behavioral outcomes of loyalty. The emotional attachment is particularly significant to financial benefit because of its impact on revenue growth (time spent and other product/service usage in the casino). The highly attached customers spend more on other services and products of the company as well as stay longer in the casino, which are very critical to increase the revenue potential of a casino. Trust was found to be a key influence on emotional attachment, word of mouth, and cooperation. It affected long-term attitudinal and behavioral inclinations that cannot easily be broken by competitive moves. Therefore, strategies and perfor- 
mances should be developed to cultivate trust towards the casino. Building switching costs also seems to work for casinos because of its effects on proportion of visit and cooperation. It should be noted that, however, the effects of switching cost were not as strong as emotional attachment and trust when the model was treated as a whole. Although building switching costs represents an efficient and tactical marketing tool for casino management to build loyalty relationships, building trust and emotional ties seems to be an effective and strategic tool to enjoy the long-term benefits of relationship marketing.

The study has several limitations that can serve as future research topics. First, the strength of relationships found should be viewed conservative in nature because of using responses to the casino brands the respondents had a feeling of loyalty. The strength of hypothesized linkages in the model would increase substantially if nonloyal customers were included. Future research should focus on loyal and nonloyal customers. The findings are also limited to the casinos targeting local customers. Further research can be extended to hotel casinos targeting out-of-town visitors. Third, the reliability of switching cost was low compared to other multi-item constructs in the study. Future research should develop more reliable measures of this construct. Future research could also treat switching cost and trust as multidimensional constructs because they were used as unidimensional constructs in this study.

The findings are limited to unidirectional influences among the variables in the model (a recursive modeling), and reciprocal relationships among the variables were not studied. For example, future research can aim to investigate reciprocal relationships among trust, switching cost, and emotional attachment. Another future research area would be a detailed investigation of antecedents of trust in hotel casino context. This would provide strategic and practical insights for hotel casinos to develop and maintain trust to their properties, and therefore, effective management of relationship marketing.

\section{APPENDIX \\ Measurement of Model Constructs}

\section{Proportion of Visit}

After converting per-month frequency to per-week frequency, the proportion of visit was calculated as a ratio of visiting casino XYZ to visiting casinos in general. In other words, Proportion of Visit $=($ question $2 /$ question 1$) \times 100$. Please note that question 1 and 2 were asked in different sections of the questionnaire.

1. How often do you visit casino(s) in [geographic area]? Please use the appropriate scale below.

If you visit once a week or more, on average, how many times do you visit per week?

$\begin{array}{llllllllll}1 & 2 & 3 & 4 & 5 & 6 & 7 & 8 & 9 & 10 \text { or more }\end{array}$


If you visit less than once a week, on average, how many times do you visit per month?

$$
\text { Less than } 1 \quad 1 \quad 2 \quad 3 \quad 4
$$

2. How often do you visit Casino XYZ in [geographic area]? Please use the appropriate scale below.

If you visit once a week or more, on average, how many times do you visit this casino per week?

$\begin{array}{llllllllll}1 & 2 & 3 & 4 & 5 & 6 & 7 & 8 & 9 & 10 \text { or more }\end{array}$

If you visit less than once a week, on average, how many times do you visit this casino per month?

$$
\begin{array}{lllll}
\text { Less than } 1 & 1 & 2 & 3 & 4
\end{array}
$$

\section{Time Spent in Casino}

On average, how many hours do you stay in this casino each time you visit? Please circle only one.

$\begin{array}{llllllllll}1 & 2 & 3 & 4 & 5 & 6 & 7 & 8 & 9 & 10 \text { or more }\end{array}$

\section{Other Product Use}

$(1=$ spend the same, $7=$ spend more, $\mathrm{x}=$ do not use, $\mathrm{n} / \mathrm{a}=$ not available $)$

1. Buffet

2. Italian restaurant

3. Mexican restaurant

4. Steak restaurant

5. Gift shops

6. Coffee shops

7. Special events

8. Movie theaters

9. Other (specify)

Note: The following multi-item measures were presented in random order in the questionnaire to avoid response bias and inflated reliability scores. Respondents rated the statements on a 7-point Likert scale ( 1 = strongly disagree, 7 = strongly agree $)$, with "don't know" options.

\section{Trust}

1. I trust the management of this casino.

2. I am certain the service I receive from this casino will be consistent from visit to visit.

3. If I make a request at this casino, no matter how trivial that request might be, it gets taken care of.

4. If I ask management or an employee a question, I feel they will be truthful to me.

5. The communication I receive from this casino (letters, promotional material, advertising) is credible.

6. When an employee at this casino says that they will do something, I am sure it will get done. 


\section{Emotional Commitment}

1. I am "emotionally attached" to this casino.

2. I have a sense of belonging to this casino.

3. The friendliness of the staff in this casino makes me feel good.

4. I enjoy visiting this casino.

5. Although there are other casino alternatives, I still like going to this casino.

\section{Switching Cost}

1. The costs in time and effort of changing this casino to another one are high for me.

2. It would be inconvenient for me to go to other casinos.

\section{Word of mouth}

1. When the topic of casinos comes up in conversations, I would recommend this casino.

2. I take pride in telling other people about my experiences in this casino.

3. I tell other people positive things about this casino.

\section{Cooperation}

1. If I saw an idea that I liked at another casino, I would share this idea with this casino's management or employees.

2. I would allow my name and a positive comment I made about this casino to be used in an advertisement.

3. I am more likely to tell management or employees about problems that occur in this casino than other casinos.

\section{REFERENCES}

Andaleeb, S. S. (1995). Dependence relations and the moderating role of trust: Implications for behavioral intentions in marketing channels. International Journal of Research in Marketing, 12, 157-172.

Anderson, J. C. \& Narus, J. A. (1990, January). A model of distributor firm and manufacturer firm working partnerships. Journal of Marketing, 54, 42-58.

Asher, H. B. (1983). Causal modeling. Quantitative applications in the social sciences series (Vol. 3). Beverly Hills, CA: Sage.

Bendapudi, N., \& Berry, L. L. (1997). Customers' motivations for maintaining relationships with service providers. Journal of Retailing, 73(1), 15-37.

Border, G. A. (1990, January). Improving casino profits through relationship marketing. Casino Gaming Magazine, 24-25.

Bowen, J. T. (1994). Casinos practice relationship marketing. The Bottom Line, 9(3), 6.

Bowen, J. T., \& Shoemaker, S. (1998, February). Loyalty: A strategic commitment. Cornell Hotel \& Restaurant Administration Quarterly, 39, 12-25.

Bowen, J. T., \& Shoemaker, S. (1999). Antecedents and consequences of loyalty for business travelers. Manuscript in preparation.

Churchill, G. A., Jr. (1979, February). A paradigm for developing better measures of marketing constructs. Journal of Marketing Research, 16, 64-73. 
Davis, J. A. (1985). The logic of causal order. Quantitative applications in the social sciences series (Vol. 55). Beverly Hills, CA: Sage.

Day, G. S. (1969, September). A two-dimensional concept of brand loyalty. Journal of Advertising Research, 9, 29-35.

Dick, A. S., \& Basu, K. (1994). Customer loyalty: Toward an integrated conceptual framework. Journal of the Academy of Marketing Science, 22(2), 99-113.

Geyskens, I., Steenkamp, J. E. M., Scheer, L. K., \& Kumar, N. (1996). The effects of trust and interdependence on relationship commitment: A trans-Atlantic study. International Journal of Research in Marketing, 13, 303-317.

Hair, J. F., Anderson, R. E., Tatham, R. L. \& Black, W. C. (1992). Multivariate data analysis with readings. New York: Macmillan.

Hennig-Thurau, T., \& Klee, A. (1997). The impact of customer satisfaction and relationship quality on customer retention: A critical reassessment and model development. Psychology \& Marketing, 14(8), 737-764.

Heun, C. T. (2000, December 11). Harrah's bets on IT to understand its customers. Information Week, pp. RB10-RB12.

Holbrook, M. B. (1981, February). Integrating compositional and decompositional analyses to represent the intervening role of perceptions in evaluative judgments. Journal of Marketing Research, 18, 13-28.

Jaros, S. J., Jermier, J. M., Koehler, J. W., \& Sincich, T. (1993). Effects of continuance, affective, and moral commitment on the withdrawal process: An evaluation of eight structural equation models. Academy of Management Journal, 36(5), 951-995.

Javalgi, R. J., \& Moberg, C. R. (1997). Service loyalty: Implications for service providers. Journal of Services Marketing, 11(3), 165-179.

Kim, W. G., Han J. S., \& Lee, E. (2001). The effects of relationship marketing on repeat purchase and word-of-mouth. Journal of Hospitality \& Tourism Research, 25(3), 272288.

Lee, M., \& Cunningham, L. F. (2001). A cost/benefit approach to understanding service loyalty. Journal of Services Marketing, 15(2), 113-130.

Malhotra, N. (1999). Marketing research: An applied orientation (3rd ed.). Upper Saddle River, NJ: Prentice Hall.

McKim, R. (1999). Betting on loyalty marketing. Target Marketing, 22(3), 42-43.

Moorman, C., Zaltman, G., \& Deshpande, R., (1992). Relationships between providers and users of market research: The dynamics of trust within and between organizations. Journal of Marketing Research, 29, 314-328.

Morgan, R., \& Hunt, S. D. (1994). The commitment-trust theory of relationship marketing. Journal of Marketing, 58(3), 20-38.

Nunnally, J. C. (1978). Psychometric theory. New York: McGraw-Hill.

Pedhazur, E. J. (1982). Multiple regression in behavioral research (2nd ed.). Fort Worth, TX: Harcourt Brace College Publishers.

Porter, M. E. (1985). Competitive advantage. New York: Free Press.

Pritchard, M. P., Havitz, M. E., \& Howard, D. R. (1999). Analyzing the commitmentloyalty link in service contexts. Journal of the Academy of Marketing Science, 27(3), 333-348.

Pritchard, M. P., \& Howard, D. R. (1997). The loyal traveler: Examining a typology of service patronage. Journal of Travel Research, 35(4), 2-10. 
Pritchard, M. P., Howard, D. R., \& Havitz, M. E. (1992). Loyalty measurement: A critical examination and theoretical extensions. Leisure Sciences, 14, 155-164.

Reichheld, F. F., \& Sasser W. E. Jr. (1990, September-October). Zero defections: Quality comes to services. Harvard Business Review, 68, 105-111.

Ruyter, K., Wetzels, M., \& Bloemer, J. (1998). On the relationship between service quality, service loyalty, and switching costs. International Journal of Service Industry Management, 9(5), 436-453.

Ryan, M. J., Rayner, R., \& Morrison, A. (1999, Summer). Diagnosing customer loyalty drivers: Partial least squares vs. regression. Marketing Research, 19-26.

Sirgy, M. J., \& Samli, A. C. (1985). A path analytic model of store loyalty involving selfconcept, store image, geographic loyalty, and socioeconomic status. Journal of Academy of Marketing Science, 13(3), 265-291.

Smith, J. B., \& Barclay, D. W. (1997). The effects of organizational differences and trust on the effectiveness of selling partner relationships. Journal of Marketing, 61, 3-21.

Swan, J. E., \& Nolan, J. J. (1985, November). Gaining customer trust: A conceptual guide for the salesperson. Journal of Personal Selling \& Sales Management, 5, 39-48.

Swan, J. E., Trawick, I. F., Rink, D. R., \& Roberts, J. J. (1988). Measuring dimensions of purchaser trust of industrial salespeople. Journal of Personal Selling \& Sales Management, 8, 1-9.

Submitted January 10, 2002

Revision Submitted November 10, 2002

Accepted December 2, 2002

Refereed Anonymously

Jun Jian Sui, graduate student, William F. Harrah College of Hotel Administration, University of Nevada, Las Vegas. Seyhmus Baloglu (e-mail: baloglu@ccmail.nevada.edu), Ph.D., associate professor, William F. Harrah College of Hotel Administration, Department of Tourism and Convention Administration, University of Nevada, Las Vegas, and visiting professor, School of Tourism and Hotel Management, Bilkent University, Ankara, Turkey. 